\title{
CORRELATION OF AXONAL REGENERATION AND SLOW COMPONENT B IN TWO BRANCHES OF A SINGLE AXON ${ }^{1}$
}

\author{
JEROME R. WUJEK AND RAYMOND J. LASEK*,2 \\ Department of Anatomy, School of Medicine, University of Maryland, Baltimore, Maryland 21201 and ${ }^{*}$ Department of \\ Anatomy, School of Medicine, Case Western Reserve University, Cleveland, Ohio 44106
}

Received December 7, 1981; Revised̉ July 19, 1982; Accepted August 24, 1982

\begin{abstract}
We investigated the relationship between slow axonal transport and axonal regeneration in the rat dorsal root ganglion (DRG) cell. The DRG cell sends out a single axon which bifurcates within the ganglion; one axon proceeds centrally into the spinal cord and the other proceeds peripherally.

The rate of axonal regeneration is approximately 2 times faster for the peripheral processes $(4.6$ $\pm 0.9 \mathrm{~mm} /$ day $)$ than for the central processes $(2.1 \pm 0.5 \mathrm{~mm} /$ day $)$. 'The peripheral and central processes regenerate through dissimilar environments (sciatic nerve and dorsal root, respectively); thus, environmental factors may account for the differences in regeneration rates. We tested this possibility by measuring the regeneration of motoneuron axons within the ventral root (histologically similar to the dorsal root). The motoneuron regeneration rate within the ventral root is similar to the motoneuron regeneration rate within the sciatic nerve, suggesting that factors within the DRG cell produce the differences in regeneration rate.

Slow axonal transport is classified into two distinct components: slow component $a$ (SCa), corresponding to the microtubule/neurofilament network of the axonal cytoskeleton, and slow component $b(\mathrm{SCb})$, corresponding to the microfilament complex/axoplasmic matrix. The transport rate of $\mathrm{SCa}$ and $\mathrm{SCb}$ in the peripheral sensory axons is approximately 2 times faster than their counterparts in the central sensory axons. SCa moves at 1.0 to $3.0 \mathrm{~mm} /$ day in the peripheral processes and 0.5 to $1.0 \mathrm{~mm} /$ day in the central processes; SCb moves at 3.5 to $6.5 \mathrm{~mm} /$ day in the peripheral processes and 2.0 to $3.5 \mathrm{~mm}$ /day in the central processes. In each branch of the DRG cell, the rate of axonal regeneration is similar to the rate of $\mathrm{SCb}$ transport. These results support the hypothesis that $\mathrm{SCb}$ is a rate-limiting factor in axonal regeneration because of its role in providing the cytoskeletal elements which are directly involved in the motility of the growth cone and elongation of the axon.
\end{abstract}

The dorsal root ganglion (DRG) cell is a pseudo-unipolar neuron which sends out a single axon that bifurcates within the ganglion, with one axon proceeding centrally into the spinal cord and the other proceeding peripherally to synapse with sensory receptors. Since these two axons arise from the same nerve cell body, one might assume that the properties of these two branches would be the same.

Investigations of various parameters have shown, however, that the central and peripheral processes of the DRG cell can differ. For example, the conduction velocity

\footnotetext{
' This research was supported by National Institutes of Health Grant NS14900-03 to R. J. L. and United States Public Health Service Traineeship HD07104 to J. R. W. We are especially grateful to Ms. Shirley liicketts for her excellent technical assistance throughout the work and Ms. Jacqueline Paul for her secretarial assistance.

" To whom correspondence should be addressed.
}

was found to be slower in the central sensory axons than in the peripheral sensory axons (Loeb, 1976; Czéh et al., 1977). Also, Czéh et al. (1977) demonstrated differential effects upon the conduction velocities following axotomy: a peripheral axotomy produced a decrease in the conduction velocity of both branches, whereas a central axotomy increased the conduction velocity of only the peripheral axons. Another example of the differential effects of axotomy is observed in studies of chromatolysis. A peripheral axotomy induces a chromatolytic reaction in the DRG cell body but a central axotomy does not lead to such morphological changes (Hare and Hinsey, 1940; Carmel and Stein, 1969). Furthermore, some properties of axonal transport differ between the two branches of the DRG cell. Although the rates of fast axonal transport are equivalent, the amount of radioactively labeled material which is moved at this rate is greater in the peripheral branch than in the central branch (Ochs, 1972). In 
studies of slow axonal transport, the rate as well as the amount of material transported is greater in the peripheral branch than in the central branch (Lasek, 1968; Mori et al., 1979).

The observation of differences in the transport of proteins in two branches of the same axon raises the interesting possibility that processes which are dependent upon these transported proteins might also differ in these two branches. One process which presumably requires the involvement of axonal transport is axonal regeneration. Fasl transport delivers membranous materials to the axon and provides for the renewal of the plasma membrane (Tessler et al., 1980; Griffin et al., 1981). Slow axonal transport represents the movement of the cytoskeletal elements such as microtubules, neurofilaments, and actin microfilaments (Lasek, 1981). Black and Lasek (1979) have proposed that the subcomponent of slow transport which they call slow component $b$ (SCb) is a primary determinant in axonal regeneration. This hypothesis is based on the observation that in the rat ventral motor neurons the rates of $\mathrm{SCb}$ (Hoffman and Lasek, 1980) and axonal regeneration (Black and Lasek, 1979) are similar. If $\mathrm{SCb}$ in nongrowing axons represents a set of processes which are directly involved in the motility of axons during regeneration, then the rate of regeneration in the central and peripheral branches of the DRG cell should be related to the rate of $\mathrm{SCb}$.

In order to test this prediction, we measured the rates of slow transport and axonal regeneration in the two branches of young adult rat DRG cells. Our study demonstrates that the peripheral axon regenerated at twice the rate of the central axon. In addition, we found that the rate of $\mathrm{SCb}$ transport is similar to the rate of regeneration. Thus, the DRG cell may be used as a model for studying the relationship between the process of axonal regeneration and intracellular mechanisms such as axonal transport.

\section{Materials and Methods}

All experimental animals were male Sprague-Dawley rats (Zivic-Miller Laboratories) weighing 250 to $300 \mathrm{gm}$. To expose the spinal roots and the DRG, laminectomies were performed on the rats, under clean conditions with $4 \%(\mathrm{w} / \mathrm{v})$ chloral hydrate used as an anesthetic. Injection of radioactive amino acids into the DRG (Lasek, 1968) was employed to investigate both axonal regeneration and axonal transport in the two branches of the DRG cell. At the end of surgery, the wound was flushed with saline, the overlying muscles and fascia were sutured with 4-0 silk thread, and the skin incision was closed with wound clips.

\section{Axonal regeneration}

Axonal regeneration was measured by radioactively labeling neuronal proteins which were subsequently axonally transported to the tips of the regenerating axons (Black and Lasek, 1976, 1979; Forman and Berenberg, 1978; Frizell and Sjöstrand, 1974; Griffin et al., 1976). Regeneration was initiated by crushing either the fifth lumbar (L5) dorsal root or the L5 spinal nerve (a major contributor to the sciatic nerve) with a no. 5 Dumont jeweler's forceps at 8 to $10 \mathrm{~mm}$ from the L5 DRG. The nerve was squeezed twice with the forceps, each squeeze lasting $10 \mathrm{sec}$; this method completely transected all axons in the nerve (data not shown). In most of the rats, $2.0 \mu \mathrm{l}$ of a $1: 1$ mixture of $\left[{ }^{3} \mathrm{H}\right]$ proline and $\left[{ }^{3} \mathrm{H}\right]$ lysine (New England Nuclear (NEN); $50 \mu \mathrm{Ci} / \mu \mathrm{l}$ in glass-distilled water) were injected into the L5 DRG in four equal doses at a rate of $0.1 \mu \mathrm{l} / \mathrm{min}$ immediately after crushing the nerve (Black and Lasek, 1979). In other rats, the regenerating axon tips were labeled via fast axonal transport (Forman and Berenberg, 1978). With this method, the wound was closed following the crush and the animal was allowed to recover for the appropriate period of time. At $18 \mathrm{hr}$ prior to sacrifice, the L5 DRG was injected with a $\left[{ }^{3} \mathrm{H}\right\rceil$ proline/ $\left[{ }^{3} \mathrm{H}\right]$ lysine mixture. With either method, the rats were sacrificed by decapitation, and the L5 DRG and the L5 dorsal root ( $30 \mathrm{~mm}$ long) or the sciatic nerve (50 to 60 $\mathrm{mm}$ long) were removed and frozen. The dorsal root, the DRG, and the sciatic nerve were cut into $1.0-\mathrm{mm}$ segments. Each segment was solubilized in $0.5 \mathrm{ml}$ of Soluene350 tissue solubilizer (Packard) at $60^{\circ} \mathrm{C}$ overnight. Five milliliters of scintillation cocktail ( $3 \mathrm{gm}$ of 2,5-diphenyloxazole plus $12 \mathrm{gm}$ of benzoic acid in 1.0 liter of toluene) were added to each sample and the radioactivity was measured in a Beckman LS-335 liquid scintillation counter.

The radioactivity per segment was plotted against distance from the DRG (Fig. 1a). In the most distal segments of the nerve, radioactivity decreased to a constant low level, which is defined by Forman and Berenberg (1978) as the background level. The point at which the high levels of radioactivity in the more proximal segments decreased to the background level distally was determined to be the leading edge of the fastest growing axons (Fig. 1a, arrows). The regeneration distances were measured from the crush site to the leading edge of the fastest growing axons.

Regeneration of motor axons within the ventral root was also examined. A laminectomy was performed, and the L5 ventral root was crushed approximately 10 to 15 mm from its spinal cord exit. Eighteen hours prior to sacrifice, the regenerating motor axons were labeled by injection of a $\left[{ }^{3} \mathrm{H}\right]$ proline $/\left[{ }^{3} \mathrm{H}\right]$ lysine mixture into the ventral horn at the L5 spinal cord level (Griffin et al., 1976; Forman and Berenberg, 1978). The animals were sacrificed at 2, 5, and 9 days. At the first two time periods, the regeneration of the motor axons was confirmed entirely to the ventral root; therefore, any radioactivity transported in the $\mathrm{L} 4$ and $\mathrm{L} 6$ ventral roots did not interfere with the measurements of regeneration distance. The entire L5 ventral root and L5 spinal nerve plus the initial portion of the sciatic nerve were removed and cut into 1.0-mm segments. Each segment was processed for radioactivity measurement as described above. The radioactivity per segment was plotted against distance from the spinal cord (Fig. 1b) and the regeneration distance for the motor axons was determined in the same manner as described for the sensory axons.

The rates of regeneration were determined by plotting the regeneration distances against time (Fig. 2). Regression lines were fit to the data points by the method of least squares, and the regeneration rates were determined from the slopes of these lines. 

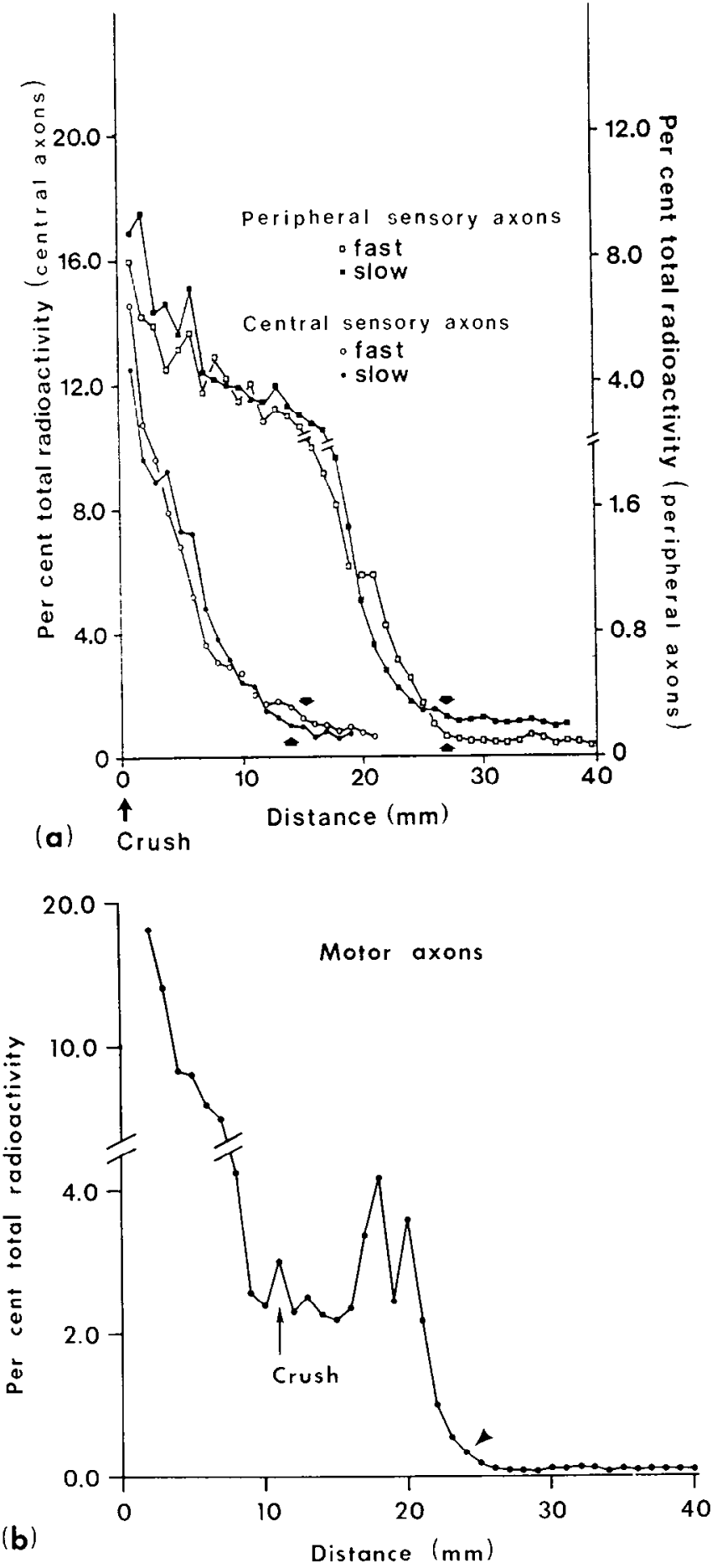

Figure 1. Distribution of radioactivily in regenerating axons plotted as a function of distance. The radioactivity in each segment is given as the percentage of the total radioactivity in the nerve. $a$, Regeneration of peripheral and central axons of the DRG cell at 7 days after axotomy. Results from the two variations of the radioisotope labeling method are compared in the two axonal branches. The technique of Forman and Berenberg (1978) is illustrated by the open squares and open circles (fast) and the technique of Black and Lasek (1979) is illustrated by the solid squares and solid circles (slow). Zero distance is the location of the crush site and the arrows point to the leading edge of the fastest growing axons. $b$, Regeneration of ventral horn motoneuron axons 5 days after a crush lesion of the L5 ventral root. Zero distance represents the exit of motor

\section{Slow axonal transport}

The L5 DRG was exposed and a total of $2.0 \mu \mathrm{l}$ of $\mathrm{L}$ $\left[{ }^{35} \mathrm{~S}\right]$ methionine (NEN; $100 \mu \mathrm{Ci} / \mu$ l in glass-distilled water) was injected into the DRG in four equal doses at a rate of $0.1 \mu \mathrm{l} / \mathrm{min}$. The animals were allowed to recover for periods of $3,7,10$, and 14 days and then were sacrificed by decapitation. Immediately, the L5 dorsal root, L5 DRG, and sciatic nerve were carefully removed and frozen. Using a Mickle gel slicer (The Mickle Laboratory Engineering $\mathrm{Co}$.), the dorsal root was cut into consecutive 2.0-mm segments, the DRG was cut out as a single segment, and the sciatic nerve was cut into consecutive 4.0-Inm segmenls. Each segment was homogenized with a ground glass microhomogenizer in $250 \mu$ of BUST (2\% $\beta$-mercaptoethanol, $8 \mathrm{~m}$ urea, $1 \%$ sodium dodecyl sulfate (SDS), and $0.1 \mathrm{~m}$ Tris (hydroxymethyl) aminomethane, $\mathrm{pH}$ 6.8); each homogenate was heated at $100^{\circ} \mathrm{C}$ for $4 \mathrm{~min}$ and then centrifuged in a Sorvall RC2-B centrifuge (15 $\min ; 15,000 \mathrm{rpm} ; 20^{\circ}$ to $24^{\circ} \mathrm{C}$ ). A $10-\mu$ l aliquot of each supernatant was added to individual scintillation vials containing $5 \mathrm{ml}$ of NEN Formula 963 scintillation cocktail. The radioactivity was measured in a Beckman LS335 liquid scintillation counter. To facilitate comparison of data among the different animals, the data were normalized by expressing the radioactivity in each segment as a percentage of the total radioactivity in the entire length of the dorsal root or sciatic nerve. 'The percentage of total radioactivity was then graphed against distance from the center of the DRG (Fig. 3).

Aliquots from the remaining supernatant $(170 \mu \mathrm{l})$ were electrophoresed on a SDS-polyacrylamide slab gel (7.5 to $15 \%$ gradient with a $4 \%$ stacking gel) as modified from Laemmli (1970). Following electrophoresis, the gels were stained with $0.1 \%$ Coomassie blue in $35 \%$ methanol and $7 \%$ acetic acid. Subsequently, the radioactive polypeptides in each gel were visualized by fluorography (Bonner and Laskey, 1974; Laskey and Mills, 1975).

\section{Results}

\section{Axonal regeneration}

Axonally transported radioactivity was used to measure the regeneration of sensory axons in the dorsal root and in the sciatic nerve following a crush lesion. Four representative examples of the radioactivity profiles obtained from regenerating sensory axons are depicted in Figure $1 a$. Moving distally from the crush site, the radioactivity level decreases progressively until it reaches background levels, as defined by Forman and Berenberg (1978). The point at which the radioactivity first reaches background level is defined as the leading edge of the fastest growing axons. The radioactivity profiles in Figure $1 a$ are like those previously described in regenerating peripheral axons of the DRG cell (Bisby, 1979).

Two variations of the radioisotope labeling method

axons from the spinal cord. The crush site is $11 \mathrm{~mm}$ from the spinal cord and the arrowhead points to the leading edge of the fastest growing axons. The L5 ventral root ends at $30 \mathrm{~mm}$ from the spinal cord; thus, all of the regeneration has taken place within the ventral root. 
have been employed in this study to measure the rate of axonal regeneration (Fig. 1a). In the technique described by Black and Lasek (1979), radioactive amino acids are injected into the DRG immediately after axotomy. Radioactive polypeptides are axonally transported during the entire regeneration period and the label is present throughout the complete length of the axon as far as the growing tip. At the time of sacrifice, a large proportion of the radioactivity is being carried by the intermediate and the slow transport components. In the technique described by Forman and Berenberg (1978), the nerve is axotomized, but the DRG is not injected until $18 \mathrm{hr}$ prior to sacrifice. Between the injection and sacrifice times, fast transport is the primary component which carries radioactivity to the tips of the regenerating axons.

Forman and Berenberg (1978) suggested that these two methods would lead to differences in the measured rates of axonal elongation. However, the results illustrated in Figure $1 a$ show that both techniques produce radioactivity profiles which are similar in waveform and in location of the leading edge of growing axons at 7 days. This is true for the other time points as well. Therefore, the data obtained from the two methods were pooled in the following analysis. It is evident from Figure $1 a$ that the peripheral branch of the DRG cell elongates faster than the central branch.

The regeneration distance was measured between the crush site and the leading edge of growing axons in 18 rats for the L5 dorsal root and in 10 rats for the sciatic nerve. These measurements are graphed in Figure 2 as a function of time after axotomy. Again, it is apparent that the regeneration rate of the peripheral branch is faster

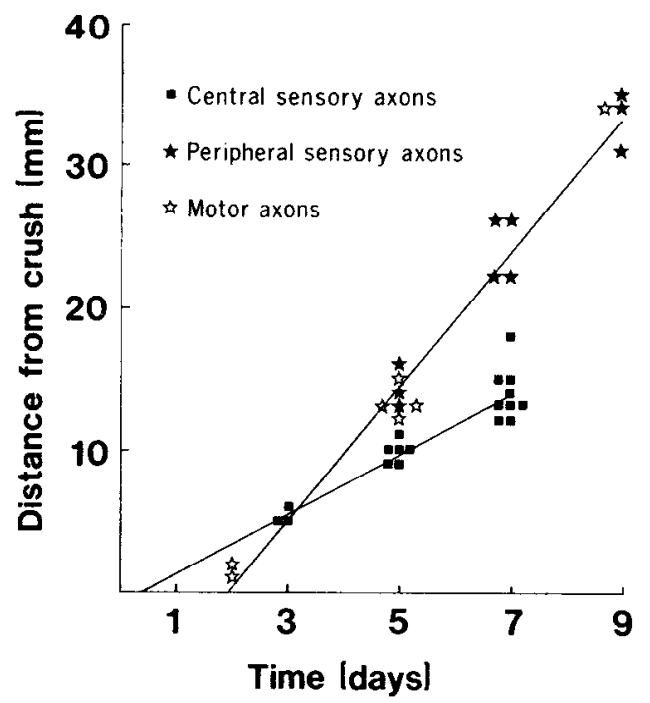

Figure 2. The regeneration distance as a function of time after the crush lesion. The individual values of regeneration distance at each time point were plotted. Regression lines were fitted to the data from the peripheral sensory axons (solid stars) and central sensory axons (solid squares) of the DRG cell by the method of least squares. The regeneration rate was determined from the slope of the regression line: peripheral sensory axons $=4.6 \pm 0.9 \mathrm{~mm} /$ day and central sensory axons $=2.1 \pm 0.5 \mathrm{~mm} / \mathrm{day}$. The open stars represent the regeneration distance of motor axons after a crush of the L5 ventral root. At 2 and 5 days post-crush, the motor axons have regenerated entirely within the ventral root. than that of the central branch. The correlation coefficient of the regression lines was 0.97 for the peripheral processes and 0.92 for the central processes, demonstrating that axonal regeneration is linear in the lwo nerves. Calculating the slopes of the regression lines provide the rate ( \pm SEM) of axonal regeneration: $4.6 \pm 0.9 \mathrm{~mm} /$ day for the peripheral processes and $2.1 \pm 0.5 \mathrm{~mm} /$ day for the central processes.

\section{Comparison of regeneration in spinal roots and peripheral nerve: Influence of environment}

It is known that external factors such as the type of lesion or the physical environment of the regenerating axons (Ramón y Cajal, 1928; Gutmann et al., 1942; Forman et al., 1979) can influence the rate of elongation. It should be noted that the amount of connective tissue, the total number of axons, and the size of nerve are greater in the sciatic nerve than in the dorsal root. Consequentlv, the crush lesion (which was applied identically to both the root and the nerve) may have been more traumatic to the dorsal root. As a result, the regeneration of the central sensory axons may have been hindered relative to the peripheral sensory axons.

The ventral horn motoneurons provide an opportunity to test this possibility because these neurons send their axons through the ventral root and into the peripheral nerves. Therefore, the regeneration of these axons can be measured both in response to crushing the spinal root and the peripheral nerve. The L5 ventral root was crushed and the rate of regeneration was measured as described under "Materials and Methods." The radioactive distribution (Fig. 1b) was similar to that seen in previous studies of regenerating ventral horn motoneurons when the sciatic nerve had been crushed (Griffin et al., 1976; Forman and Berenberg, 1978; Bisby, 1979). The regeneration distances are plotted in Figure 2 (open stars); the rate of regeneration in the ventral root was $4.6 \mathrm{~mm} /$ day, which is similar to that found for motor axons crushed in the sciatic nerve (Bisby, $1979(3.9 \mathrm{~mm} /$ day); Black and Lasek, 1979 (3.8 mm/day); Forman and Berenberg, 1978 (4.4 mm/day); Griffin et al., 1976 (4.4 $\mathrm{mm} /$ day $^{3}$ ); Pestronk et al., $1980(4.5 \mathrm{~mm}$ /day)). These results demonstrate that ventral horn motoneurons regenerate their axons through the spinal root and peripheral nerve at essentially the same rate. The small differences in the rates reported by these studies probably results from minor differences in the way the axons were interrupted. It has been clearly established that the type of trauma inflicted on the connective tissue will produce differences in regeneration rates (Ramón y Cajal, 1928; Gutmann et al., 1942; Forman et al., 1979). For example, the lowest of these values was obtained by Black and Lasek (1979) who crushed the nerve with a hemostat, injuring $3 \mathrm{~mm}$ or more of the nerve. In the present study and in others where the rate was slightly faster, fine forceps were employed to crush the nerve, thus injuring a more limited region. Hence, the normal histological differences between ventral root and peripheral nerve are not sufficient to alter the rate of axonal regeneration. The histological characteristics of the ventral root are

'Lata corrected for latency period. 
very similar to those of the dorsal root (Haller and Low, 1971; Haller et al., 1972). Thus, the environmental factors of the dorsal root should not significantly alter the regeneration rate of the central axons of the DRG cell. Rather, the difference in regeneration rate between central and peripheral sensory axons is probably due to factors intrinsic to the DRG cell.

\section{Axonal transport}

The slow axonal transport of radioactively labeled polypeptides in the two branches of the DRG cell was examined in 18 rats. Because the amount of radioactivity incorporated by the cells was variable from experiment to experiment, the data were normalized to facilitate comparisons among the different animals. The profiles of slowly transported radioactivity have complex waveforms; although the minor peaks consistently appear in the distribution, in this paper, we will focus on the major aspects of the radioactive waves which correspond to $\mathrm{SCa}$ and $\mathrm{SCb}$.

Two slowly moving groups of axonally transported proteins can be identified in each branch of the DRG cells. Figure 3 depicts the slow transport of total radio- activity in the dorsal root (central branch) and sciatic nerve (peripheral branch) at $3,7,10$, and 14 days postinjection (PI). In both branches, a wavefront of radioactivity can be observed at 3 days PI. By 7 days PI, each wavefront has moved further from the DRG and a peak of radioactivity has appeared at the crest of the wavefront. At 10 days PI in each branch, the initial peak of radioactivity has moved further away and is now followed by a second, larger peak of radioactivity. At 14 days PI, only a trailing edge of the initial peak is visible, while the second wave has continued to move further out from the DRG.

The rate of movement of these waves was determined from the radioactivity profiles of all 7-, 10-, and 14-day animals. The transport rate of each wave is described by a range of values indicating the movement of the peak and wavefront (Hoffman and Lasek, 1980). The peak is the highest level of radioactivity and the wavefront is the region of rapidly decreasing radioactivity distal to the peak. Measurements of the wavefront movement were taken from the lowest level of radioactivity in the wave (i.e., the foot of the wave). The distance of the peak and wavefront of radioactivity from the DRG was measured
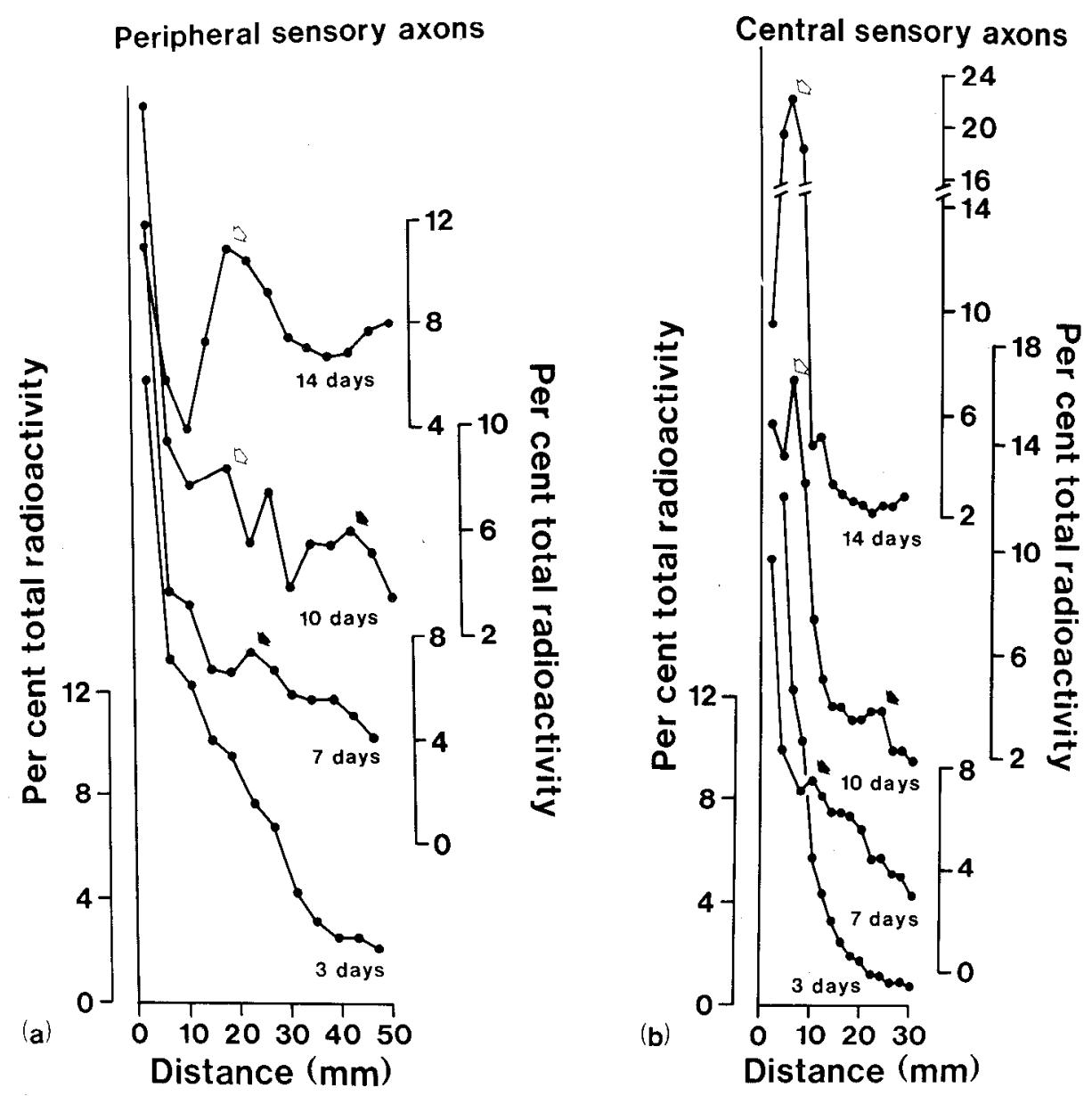

Figure 3. Axonal transport of total radioactivity in the peripheral sensory axons and central sensory axons of the DRG cell at $3,7,10$, and 14 days postinjection. To facilitate comparison of data from different animals, the data were normalized by expressing the radioactivity in each segment as a percentage of the total radioactivity in the entire length of the nerve. The percentage of total radioactivity was graphed as a function of distance from the center of the DRG. The solid arrows indicate the initial wave of radioactivity $(\mathrm{SCb})$ and the open arrows indicate the second wave of radioactivity (SCa). $a$, Peripheral processes; $b$, central processes. 
in each animal and divided by time (days) to obtain the transport rates. In the peripheral sensory axons, the rates $( \pm$ SEM) for the initial wave are $3.5 \pm 0.7 \mathrm{~mm} /$ day to 6.5 $\pm 0.4 \mathrm{~mm} /$ day; the second wave moves at a rate of 1.0 $\pm 0.3 \mathrm{~mm} /$ day to $3.0 \pm 0.7 \mathrm{~mm} /$ day. In the central sensory axons, the initial wave moves at a rate of $2.0 \pm$ $0.5 \mathrm{~mm} /$ day to $3.5 \pm 0.3 \mathrm{~mm} /$ day; the second wave moves at a rate of $0.5 \pm 0.2 \mathrm{~mm} /$ day to $1.0 \pm 0.3 \mathrm{~mm} /$ day. The transport rates of the second wave correspond to values found for slow transport of total radioactivity in the peripheral and central branches of the DRG cell (Lasek, 1968; Komiya and Kurokawa, 1978). It is apparent that the transport rate of each wave in the peripheral process is approximately twice that of its counterpart in the central process.

Black and Lasek (1980) have demonstrated that slow axonal transport consists of two components called slow components $a(\mathrm{SCa})$ and slow component $b$ (SCb). Following a pulse label of radioactivity, the two components appear as separate waves of radioactivity with $\mathrm{SCb}$ moving ahead of SCa. The two waves of radioactivity being transported in the sciatic nerve and dorsal root may represent the movement of $\mathrm{SCa}$ and $\mathrm{SCb}$ in the DRG cell. The polypeptide composition of the radioactively labeled waves was analyzed by one-dimensional SDSPAGE (Fig. 4). The polypeptide bands in the initial wave

\section{$\mathrm{SCa}$}

\section{Peripheral Central}

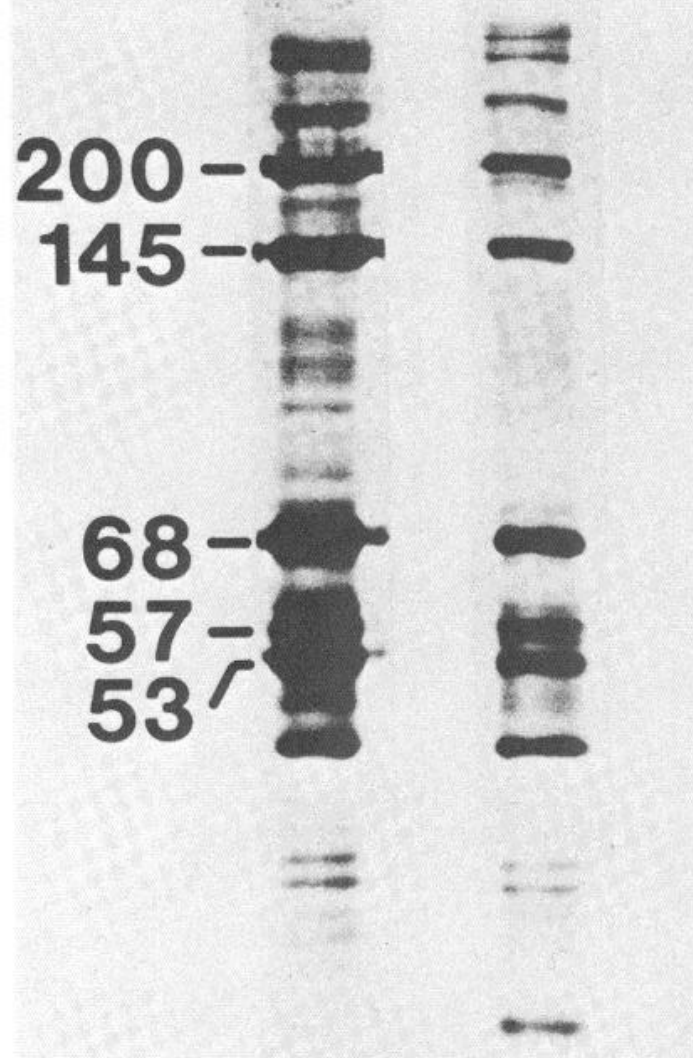

\section{$\mathrm{SCb}$}

Peripheral Central

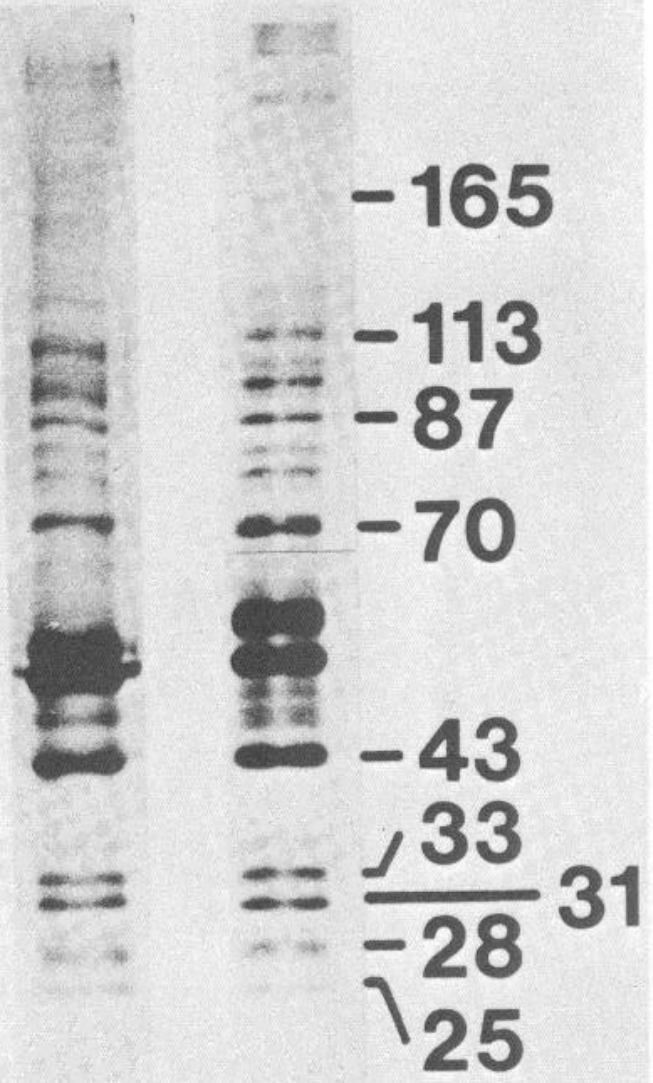

Figure 4. Comparison of $\mathrm{SCa}$ and $\mathrm{SCb}$ in the peripheral and central processes of the DRG cell. The samples were taken from nerve segments corresponding to the first and second waves of radioactivity in both the sciatic nerve and the dorsal root. The polypeptide composition was analyzed by SDS-PAGE and fluorography (as described under "Materials and Methods"). The apparent molecular weights of selected polypeptide bands are listed in units of $10^{3}$ daltons alongside the fluorographs. In SCa (second wave), the polypeptide composition is identical for both branches; the primary constituents are neurofilament proteins $(200,000,145,000$, and 68,000 daltons) and tubulin (57,000 and 53,000 daltons). In SCb (first wave), the polypeptide composition is also identical for both branches. However, the $\mathrm{SCb}$ composition is markedly different from that of SCa. 
are identical between the peripheral and central processes; similarly, the polypeptide bands in the second wave are identical between the two processes. However, the composition between the first and second wave is markedly different. The most prominent constituents of the second wave are the neurofilament triplet proteins $(200,000,145,000$, and 68,000 daltons) and tubulin $(57,000$ and 53,000 daltons), which have been identified as the primary elements of SCa (Lasek and Hoffman, 1976; Black and Lasek, 1980). The composition of the first wave shows a strong similarity to the polypeptide composition of SCb (Black and Lasek, 1980; Garner and Lasek, 1981). Fluorographs of slow transport in the two branches of the DRG cell (Mori et al., 1979; J. R. Wujek and R. J. Lasek, manuscript in preparation) reveal the presence of two distinct polypeptide groups, each moving at a separate rate. Thus, the first and second wave of slowly transported radioactivity represent the movement of $\mathrm{SCb}$ and $\mathrm{SCa}$, respectively, in the peripheral and central process of the DRG cell.

\section{Discussion}

"If we consider the character of the notions that we have acquired concerning nervous regeneration, we may note that they can be classified into two categories: (1) those which have to do with internal, immanent properties or tendencies of the neuronal protoplasm, acting in relative independence of their surroundings; and (2) those which have to do with reactions of this protoplasm brought about by the mechanical or chemical conditions of the region traversed. As an abbreviation we shall designate these two groups of manifestations respectively: intrinsic and extrinsic phenomena." (Ramón y Cajal, 1928).

These intrinsic and extrinsic properties together will contribute to the ultimate outcome of the regenerative process. But certain properties will exert a more fundamental effect upon this process. Because the regenerating axon is an outgrowth of the neuron (Harrison, 1910), those properties which are intrinsic to the neuron will be essential and formative elements of the regenerative process. Our discussion shall focus upon intrinsic properties which give rise to axonal regeneration. In particular, we propose that a direct relationship exists between $\mathrm{SCb}$ and axonal regeneration, because $\mathrm{SCb}$ represents the movement of cytoskeletal elements which are directly involved in axonal motility.

\section{Correlation between $S C b$ and axonal regeneration}

In Table I, the transport rates of $\mathrm{SCa}$ and $\mathrm{SCb}$ are compared with the rates of axonal regeneration in the

TABLE I

Rates of slow axonal transport and axonal regeneration in the dorsal root ganglion cell

\begin{tabular}{|c|c|c|c|c|c|}
\hline & \multicolumn{2}{|c|}{$\mathrm{SCa}(\mathrm{mm} / \mathrm{day})^{\prime \prime}$} & \multicolumn{2}{|c|}{$\mathrm{SCb}(\mathrm{mm} / \text { day })^{\prime \prime}$} & \multirow{2}{*}{$\begin{array}{c}\text { Regeneration } \\
\text { (mm/day) }\end{array}$} \\
\hline & Peak & Wavefront & Peak & Wavefront & \\
\hline $\begin{array}{c}\text { Peripheral } \\
\text { branch }\end{array}$ & $1.0 \pm 0.3$ & $3.0 \pm 0.7$ & $3.5 \pm 0.7$ & $6.5 \pm 0.4$ & $4.6 \pm 0.9$ \\
\hline $\begin{array}{l}\text { Central } \\
\text { branch }\end{array}$ & $0.5 \pm 0.2$ & $1.0 \pm 0.3$ & $2.0 \pm 0.5$ & $3.5 \pm 0.3$ & $2.1 \pm 0.5$ \\
\hline
\end{tabular}

"The values are \pm standard error of the mean. two branches of the DRG cell. For each branch, a close correlation can be observed between the rate of $\mathrm{SCb}$ transport and the rate of axonal regeneration. In the peripheral sensory axons of the rat, $\mathrm{SCb}$ moves at 3.5 to $6.5 \mathrm{~mm} /$ day and the regeneration rate is $4.6 \mathrm{~mm}$ /day; in the central sensory axons, $\mathrm{SCb}$ moves at 2.0 to $3.5 \mathrm{~mm} /$ day and the regeneration rate is $2.1 \mathrm{~mm} /$ day. This evidence indicates that the rate of $\mathrm{SCb}$ transport is related to the rate of axonal regeneration.

The rate of $\mathrm{SCb}$ transport correlates with the rate of axonal regeneration in other neurons as well as in the DRG cell. This is the case in the rat ventral horn motoneuron, where the rates of both $\mathrm{SCb}$ (Hoffman and Lasek, 1975, 1980; Lasek and Hoffman, 1976; McQuarrie et al., 1980) and axonal regeneration (Bisby, 1979; Black and Lasek, 1979; Forman and Berenberg, 1978; Griffin et al., 1976; Pestronk et al., 1980) are approximately $4 \mathrm{~mm} /$ day. Similarly, in the goldfish retinal ganglion ecll, the rates for SCb (I. G. McQuarrie, personal communication) and axonal regeneration (McQuarrie and Grafstein, 1978, 1981) are 0.2 to $0.5 \mathrm{~mm} /$ day.

\section{Role of $\mathrm{SC} b$ in axonal elongation}

Many processes intrinsic to the neuron potentially contribute to the complex phenomenon of axonal regeneration (Grafstein and McQuarrie, 1978). One such process is axonal transport. 'Through this process, the macromolecules necessary for the construction and maintenance of the regenerating axon are conveyed from the cell body into the new sprout. The correlation between the rates of $\mathrm{SCh}$ and regeneration suggests that $\mathrm{SCh}$ transport represents the movement of structures which are directly involved in the motility of the regenerating axon and thus governs its rate of growth.

Although the correlation between the two rates is good, this correlation is not exact. Slow component $b$ moves as a broad wave of radioactivity in both branches of the DRG cell; the rate of movement is described by a range of values determined from the peak and wavefront of radioactivity. The radioisotope labeling technique measures the rate of the fastest regenerating axons. It is apparent from Table I that the leading edge of these axons moves at a rate somewhat slower than the rate determined for the leading edge of the $\mathrm{SCb}$ wave. Since these rates do not correlate exactly, the possibility arises that the similarity between the rates of $\mathrm{SCb}$ and regeneration is merely coincidental. We propose that this is not the case and that the similarity between these rates results from the central role that the $\mathrm{SCb}$ proteins play in the motility of regenerating axons. Furthermore, the observation that regeneration is slightly slower than $\mathrm{SCb}$ can be explained if other processes, which must be coordinated with the movement of $\mathrm{SCb}$ proteins during regeneration, further constrain the movement of $\mathrm{SCb}$. One such process is the movement of the cytoskeletal elements of SCa, which move more slowly than those of SCb (Black and Lasek, 1980; Hoffman and Lasek, 1975; Lasek and Hoffman, 1976). The coordinated movement of these structures in $\mathrm{SCb}$ and $\mathrm{SCa}$, which are both required for regeneration, may result in an aggregate rate of movement which is somewhat slower than the fastest moving $\mathrm{SCb}$ proteins in nongrowing axons. The fastest moving $\mathrm{SCb}$ proteins provide a measure of the most 
efficient translocation of this group of proteins unhindered by other more slowly moving structures. In regenerating axons, $\mathrm{SCb}$ is not sufficient in itself to supply all of the ingredients for axonal elongation. Neurofilaments are also present in regenerating axons (Yamada et al., $1970,1971)$ but these structures are conveyed only by SCa (Black and Lasek, 1980).

\section{$S C b$ and the growth cone}

Two fundamental steps in the process of axonal regeneration are growth cone formation and axonal elongation (Ramón y Cajal, 1928; Young, 1942). The growth cone is the motile organelle of a regenerating axon; as such, it must ultimately determine the rate of axonal regeneration because the axon can never elongate faster than the growth cone can move. The growth cone is characterized by two sets of dynamic structures (Yamada et al., 1971; Chang and Goldman, 1973; Letourneau, 1979, 1981): (i) a set of membranous organelles which interact with the plasma membrane and (ii) an internal scaffolding which consists principally of actin microfilaments. The membranous system is supplied by the fast component of axonal transport (Tessler et al., 1980; Griffin et al., 1981) which moves at $400 \mathrm{~mm} /$ day in the DRG cell (Lasek, 1968; Ochs, 1972).

It does not seem probable that the fast component will limit the rate at which the growth cone will move because the fast component can deliver materials at rates which are 100 times faster than regeneration. Although fast transport may not limit the rate of regeneration, it is clearly necessary and probably regulates other aspects of regeneration such as the initiation of sprouting.

The proteins which comprise the microfilament network of the growth cone are supplied by SCb (Black and Lasek, 1980; Brady and Lasek, 1981; Brady et al., 1981). For example, $\mathrm{SCb}$ supplies actin, clathrin, and a number of other proteins which have been associated with the internal scaffolding of the growth cone. These proteins not only comprise the fabric of the growth cone but also the internal structure of the microspikes, which are the vanguard of axonal growth. Clearly, axons cannot extend any faster than the rate at which these proteins can be supplied.

The similarity between the rate of $\mathrm{SCb}$ and the rate of regeneration suggests that the rate of protein translocation in $\mathrm{SCb}$ may set the limits on the rate of regeneration when the axon is severed. If this is the case, then the relationship between the rate of $\mathrm{SCb}$ and regeneration may be more fundamental than limitations inherent in the supply of proteins required to construct the growth cone. It is possible that the motile mechanism which is responsible for the translocation of $\mathrm{SCb}$ in the mature axon is also directly involved in the motility of the growth cone. It is commonly thought that extension of the growth cone is an actin dependent process (Yamada et al., 1971; Letourneau, 1981). Slow component $b$ corresponds to a structural complex which consists of actin, a variety of metabolic enzymes, and regulatory proteins such as calmodulin (Black and Lasek, 1980; Brady and Lasek, 1981; Brady et al., 1981). These proteins move together in the axon as a structural assembly. This structural assembly is a prime candidate for the force gener- ating structure in the axon. Many of the proteins, in addition to actin, which are present in $\mathrm{SCb}$ are also characteristic of the striated muscle sarcomere. For example, creatine phosphokinase, which is an SCb protein (Brady and Lasek, 1981), is structurally associated with the contractile apparatus of skeletal muscle (Mani and Kay, 1976; Walliman et al., 1978). Calmodulin, which is another SCb protein (Brady et al., 1981), appears to be involved in the regulation of myosin in smooth muscle and nonmuscle cells (Cheung, 1980).

We propose that $\mathrm{SCb}$ contains a primary component of the axonal motile complex which is responsible for the active translocation of the cytoskeleton in the axon and that during regeneration this motile complex is directly involved in the locomotion of the growth cone. If $\mathrm{SCb}$ is a primary motile structure, then in the nongrowing axons it could generate the forces responsible both for its own movement and for the movement of microtubules and neurofilaments which trail behind SCb. When the axon is severed, these motile complexes, which are in transit along the axon, could be reorganized at the transection site to form the motile components of the growth cone leading to the extension of regenerative sprouts.

\section{References}

Bisby, M. A. (1979) Differences in incorporation of axonally transported protein in regenerating motor and sensory axons. Exp. Neurol. 65: 680-684.

Black, M. M., and R. J. Lasek (1976) 'l'he use of axonal transport to measure axonal regeneration in rat ventral motor neurons. Anat. Rec. 184: 360-361.

Black, M. M., and R. J. Lasek (1979) Slowing of the rate of axonal regeneration during growth and maturation. Exp. Neurol. 63: 108-119.

Black, M. M., and R. J. Lasek (1980) Slow components of axonal transport: Two cytoskeletal networks. J. Cell Biol. 86: 616-623.

Bonner, W. M., and R. A. Laskey (1974) A film detection method for tritium-labeled proteins and nucleic acids in polyacrylamide gels. Eur. J. Biochem. 46: 83-88.

Brady, S. T., and R. J. Lasek (1981) Nerve-specific enolase and creatine phosphokinase in axonal transport: Soluble proteins and the axoplasmic matrix. Cell 23: 515-523.

Brady, S. T., M. Tytell, K. Heriot, and R. J. Lasek (1981) Axonal transport of calmodulin: A physiologic approach to identification of long-term associations between proteins. J. Cell Biol. 89: 607-614.

Carmel, P. W., and B. M. Stein (1969) Cell changes in sensory ganglia following proxinal and distal nerve section in the monkey. J. Comp. Neurol. 135: 145-166.

Chang, C. M., and R. D. Goldman (1973) The localization of actin-like fibers in cultured neuroblastoma cells as revealed by heavy meromyosin binding. J. Cell Biol. 57: 867-874.

Cheung, W. Y. (1980) Calmodulin plays a pivotal role in cellular regulation. Science 207: 19-27.

Czéh, G., N. Kudo, and M. Kuno (1977) Membrane properties and conduction velocity in sensory neurones following central or peripheral axotomy. J. Physiol. (Lond.) 270: 165-180.

Forman, D. S., and R. A. Berenberg (1978) Regeneration of motor axons in the rat sciatic nerve studied by labeling with axonally transported radioactive proteins. Brain Res. 156: $213-226$.

Forman, D. S., D. K. Wood and S. DeSilva (1979) Rate of regeneration of sensory axons in transected rat sciatic nerve repaired with epineurial sutures. J. Neurol. Sci. 44: 55-59. 
Frizell, M., and J. Sjöstrand (1974) The axonal transport of slowly migrating $\left[{ }^{3} \mathrm{H}\right]$ leucine labeled proteins and the regeneration rate in regenerating hypoglossal and vagus nerves of the rabbit. Brain Res. 81: 267-283.

Garner, J. A., and R. J. Lasek (1981) Clathrin is axonally transported as part of slow component $b-$ The microfilament complex. J. Cell Biol. 88: 172-178.

Grafstein, B., and I. G. McQuarrie (1978) Role of the nerve cell body in axonal regeneration. In Neuronal Plasticity, C. W. Cotman, ed., pp. 155-195, Raven Press, New York.

Griffin, J. W., D. B. Drachman, and D. B. Price (1976) Fast axonal transport in motor nerve regeneration. J. Neurobiol. 7: $355-370$.

Griffin, J. W., D. L. Price, D. B. Drachman, and J. Morris (1981) Incorporation of axonally transported glycoproteins into axolemma during nerve regeneration. J. Cell Biol. 88: 205-214.

Gutmann, E., L. Gutmann, P. B. Medawar, and J. Z. Young (1942) The rate of regeneration of nerve. J. Exp. Biol. 19: 1444.

Ialler, F. R., and F. N. Low (1971) The fine structure of the peripheral nerve root sheath in the subarachnoid space in the rat and other laboratory animals. Am. J. Anat. 131: 1-20.

Haller, F. R., A. C. Haller, and F. N. Low (1972) The fine structure of cellular layers and connective tissue space at spinal nerve root attachment in the rat. Am. J. And. 133: 109-124.

Hare, W. K., and J. C. Hinsey (1940) Reactions of dorsal root ganglion cells to section of peripheral and central processes. J. Comp. Neurol. 73: 489-502.

Harrison, R. G. (1910) The outgrowth of the nerve fiber as a mode of protoplasmic movement. J. Exp. Zool. 9: 787-848.

Hoffman, P. N., and R. J. Lasek (1975) The slow component of axonal transport. Identification of major structural polypeptides of the axon and their generality among mammalian axons. J. Cell Biol. 66: 351-356.

Hoffman, P. N., and R. J. Lasek (1980) Axonal transport of the cytoskeleton in regenerating motor neurons: Constancy and change. Brain Res. 202: 317-333.

Komiya, Y., and M. Kurokawa (1978) Asymmetry of protein transport in two branches of bifurcating axons. Brain Res. 139: 354-358.

Laemmli, U. K. (1970) Cleavage of structural proteins during the assembly of the head of bacteriophage T4. Nature 227: 680-685.

Lasek, R. J. (1968) Axoplasmic transport in cat dorsal root ganglion cells: As studied with $\left[{ }^{3} \mathrm{H}\right]$ leucine. Brain Res 7: 360377.

Lasek, R. J. (1981) The dynamic ordering of neuronal cytoskeletons. Neurosci. Res. Program Bull. 19: 7-32.

Lasek, R. J., and P. N. Hoffman (1976) The neuronal cytoskeleton, axonal transport and axonal growth. In Cell Motility, R. Goldman, T. Pollard, and J. Rosenbaum, eds., pp. 10211049, Cold Spring Harbor Laboratory, Cold Spring Harbor, New York.
Laskey, R. A., and A. D. Mills (1975) Quantitative film detection of ${ }^{3} \mathrm{H}$ and ${ }^{14} \mathrm{C}$ in polyacrylamide gels by fluorography. Eur. J. Biochem. 56: 335-341.

Letourneau, P. C. (1979) Cell-substratum adhesion of neurite growth cones and its role in neurite elongation. Exp. Cell Res. 124: $127-138$.

Letourneau, P. C. (1981) Immunocytochemical evidence for colocalization in neurite growth cones of actin and myosin and their relationship to cell-substratum adhesions. Dev. Biol. 85: 113-2.

Loeb, G. E. (1976) Decreased conduction velocity in the proximal projection of myelinated dorsal root ganglion cells in the cat. Brain Res. 103: 381-385.

Mani, R. S., and C. M. Kay (1976) Physicochemical studies on the creatine kinase $\mathrm{M}$-line protein and its interaction with myosin-fragments. Biochem. Biophys. Acta 453: 391-399.

McQuarrie, I. G., and B. Grafstein (1978) Protein synthesis and fast axonal transport in regenerating goldfish retinal ganglion cells: Effect of a conditioning lesion. Soc. Neurosci. Abstr. 4: 533.

McQuarrie, I. G., and B. Grafstein (1981) Effect of a conditioning lesion on optic nerve regeneration in goldfish. Brain Res. 216: 253-264.

McQuarrie, I. G., S. T. Brady, and R. J. Lasek (1980) Polypeptide composition and kinetics of $S C a$ and $S C b$ in sciatic nerve motor axons and optic axons of the rat. Soc. Neurosci. Abstr. 6: 501

Mori, H., Y. Komiya, and M. Kurokawa (1979) Slowly migrating axonal polypeptides. Inequalities in their rate and amount of transport between two branches of bifurcating axons. J. Cell Biol. 82: 174-184.

Ochs, S. (1972) Rate of fast axoplasmic transport in mammalian nerve fibres. J. Physiol. (Lond.) 227: 627-645.

Pestronk, A., D. B. Drachman, and J. W. Griffin (1980) Effects of aging on nerve sprouting and regeneration. Exp. Neurol. 70: $65-82$

Ramón y Cajal, S. (1928) Degeneration and Regeneration of the Nervous System, R. M. May, ed., Oxford University Press, Cambridge, England.

Tessler, A., L. Autilio-Gambetti, and P. Gambetti (1980) Axonal growth during regeneration: A quantitative autoradiographic study. J. Cell Biol. 87: 197-203.

Walliman, T., G. Pelloni, D. G. 'T'urner, and H. M. Eppenburger (1978) Monovalent antibodies against MM-creatine kinase remove the M-line from myofibrils. Proc. Natl. Acad. Sci. U.S. A. 75: 4296-4300.

Yamada, K. M., B. S. Spooner, and N. K. Wessells (1970) Axon growth: Role of microfilaments and microtubules. Proc. Natl. Acad. Sci. U. S. A. 66: 1206-1212.

Yamada, K. M., B. S. Sponner, and N. K, Wessells (1971) Ultrastructure and function of growth cones and axons of cultured nerve cells. J. Cell Biol. 49: 614-635.

Young, J. Z. (1942) The functional repair of nervous tissue. Physiol. Rev. 22: 318-374. 